\title{
A Study on the Epidemiology and Aetiology of Acute Gastroenteritis in Adult Patients Presenting at the Infectious Diseases Hospital in Tirana, Albania
}

\author{
Gentian P. Stroni ${ }^{1}$, Majlinda M. Dhimolea ${ }^{2}$, Pëllumb S. Pipero ${ }^{1}$, Dhimiter V. Kraja ${ }^{1}$, Suela Y. Sallavaci ${ }^{3}$, Silva F. Bino ${ }^{2}$ \\ ${ }^{1}$ Infectious Diseases Hospital, University Hospital Centre "Mother Theresa", Tirana, Albania \\ ${ }^{2}$ Institute of Public Health, Tirana, Albania \\ ${ }^{3}$ University Hospital Centre "Mother Theresa", Tirana, Albania
}

Background: Acute gastroenteritis remains a common cause of hospital emergency room visits in Albania. However, the aetiology of severe gastroenteritis leading to hospitalization in adults frequently remains unclear.

Aims: Our objective was to study the epidemiology and causes of community-acquired, acute gastroenteritis in adult patients presenting to hospital.

Study Design: Cross sectional study.

Methods: A prospective study was conducted from January 2010 to January 2012, among patients $\geq 15$ years old with community-acquired gastroenteritis presenting to the emergency room of the University Hospital "Mother Theresa" in Tirana, Albania. Stool samples and rectal swabs were collected from the patients for microbiological testing. Results: The median age of the study patients was 33 (15-88) years and $577(58 \%)$ were females. The median age of males was $35(15-87)$ years. The vast majority of cases occurred in urban area $(849,85 \%)$, $\mathrm{p}<0.01$. Patients were admitted throughout the year with peak admissions for patients infected by bacterial pathogens in summer and those affected by viral pathogens in autumn. A total of $917(91.7 \%)$ patients underwent a laboratory examination. The overall isolation rate was $51 \%$. Bacterial pathogens were found in $29 \%$, viral pathogens in $19 \%$ and protozoal pathogens in $2.5 \%$ of patients. No aetiological agent or other cause of acute diarrhoea was found in 449 (49\%) patients. Twenty-nine (3.2\%) patients were hospitalized.

Conclusion: Despite extensive laboratory investigations, enteropathogens were detected in only $51 \%$ of adult patients who presented to the hospital ER with acute gastroenteritis. Viral infections ranked as the second most common cause of gastroenteritis in adults.

(Balkan Med J 2014;31:196-201).

Key Words: Aetiology, diarrhoea, enteropathogens, epidemiology

\section{INTRODUCTION}

The main factor that influences the high rates of morbidity and mortality within developing nations is diarrhoeal diseases. However, acute diarrhoeal diseases are also prevalent within nations that maintain high sanitary levels $(1,2)$. This has been attributed to an increase in acute gastrointestinal illnesses within Europe due to the identification of various microorganisms that enhance the prevalence of such infections $(3,4)$. The prevalence of diarrhoeal infections led to the introduction of the diarrhoeal disease control programme by the World Health Organization (WHO) $(1,2)$. This programme was based upon the cholera outbreak experienced in Albania in 1994. The programme enhanced the development of better healthcare conditions through the provision of a clean water supply, sanitation and hygiene, which was intended to enhance the health status of individuals (1).
The majority of bacterial enteric infections are transmitted through food, with the influencing risk factors varying according to the bacteria involved $(5,6)$. The majority of studies have placed an emphasis on the epidemiology and aetiology pertaining to diarrhoeal infections among children, and there has been limited research pertaining to the epidemiology of gastroenteritis among adults within Albania (7). This is attributed to the most recent diarrhoea case management system introduced in the 1990s, which does not incorporate the modern diarrhoeal changes experienced by adults (1). Diarrhoea refers to the movement of four or more liquid stools per day among individuals in a manner that is not normal in relation to normal stool passage. Diarrhea seeks to identify the initial symptoms of gastrointestinal infections, which may be attributed to a variety of organisms including bacteria, viruses and parasites (8). The infection is spread to other individuals 
through contaminated food or water or the existence of poor levels of hygiene within the surroundings. Severe diarrhoea may lead to high levels of fluid loss, which may ultimately be rendered life threatening among young children and adults who are malnourished or have low immunity levels $(9,10)$.

\section{MATERIAL AND METHODS}

This prospective study presents several findings based upon research conducted on patients older than 15 years of age admitted to the 'Mother Teresa' University Hospital Centre in Tiran from January 2010 to January 2012, suffering from acute gastroenteritis. This study seeks to provide an updated epidemiological and aetiological analysis pertaining to acute gastrointestinal infections identified within the emergency rooms among developing countries through the provision of Albania as a case study. The data obtained from the study may be utilized in developing further research geared towards improving the epidemiological surveillance of acute gastrointestinal illnesses. We conducted an analysis of patients older than 15 years of age admitted to the emergency room within the Mother Teresa University Hospital in Tirana between January 2010 and January 2012 suffering from acute gastroenteritis, which was identified as the primary form of diagnosis. The study protocol was approved by the Ethics Committee of the University of Tirana. Written consent was obtained from all patients. The study followed the protocol stipulated within the Declaration of Helsinki through the inclusion of good clinical practice guidelines together with national stipulations.

The inclusion criterion was complaints pertaining to diarrhoea that involved three liquid stools within 24 hours. Several definitions have been developed pertaining to acute diarrhoea. The most commonly used definition identifies diarrhoea as the passage of three or more watery stools in a period of 24 hours and lasting for less than a 2 -week period. The identification of these symptoms leads to the diagnosis of infective gastroenteritis. Acute diarrhoea may develop as a consequence of other intra-abdominal and systemic infections. The World Health Organization provides a diarrhoea definition that states that diarrhoea refers to the passage of three or more liquid stools within a day in a manner that is more frequent in comparison to the normal passage experienced by the individual.

The hospital requires that stool cultures should be provided in the case of severe diarrhoea, which is identified as the passage of six or more liquid stools within a 24-hour period (11). All patients observed within the study had visited the hospital within 3 days of inception of the illness. Individuals presenting to the ER were provided treatment on an outpatient basis or were admitted to the infectious diseases ward. The study sought to exclude patients suffering from immunecompromised illnesses together with patients suffering from inflammatory bowel disease together with chronic diarrhoea. Following their diagnosis within the ER and admission to the ward, the patients provided one stool specimen or rectal swab for microbiological examination. Faecal specimens were examined for various pathogens of viral, bacterial or parasitic nature. Demographic and clinical features together with laboratory results pertaining to each patient involved within the study were recorded. Potential pathogens were diagnosed through the utilization of standard laboratory processes (11-14). Stool samples were examined for the presence of various pathogens and parasites including Salmonella, Shigella, Escherichia and Campylobacter, using standard laboratory procedures.

For isolation of Salmonella and Shigella, the stool sample was cultured on Salmonella - Shigella (SS) agar, McConkey agar (Biomedics, bioMérieux, Madrid, Spain), and selenite F-broth, and sub-cultured through the utilization of SS-agar with 24 hours incubation. This was followed by incubation on nutrient media at $37^{\circ} \mathrm{C}$ within the stipulated aerobic conditions. Consequent identification was conducted upon the utilization of biochemical processes that enhanced his antigen structure detection. E. coli was identified following culturing on McConkey agar (Biomedics, bioMérieux, Madrid, Spain), using a biochemical array. The group determination process was identified through agglutination utilizing specific hyperimmune sera on a glass plate. This was followed by the isolation of bacteria pertaining to the genus Campylobacter via incubation on Blaser's solid medium for 48 hours at $37^{\circ} \mathrm{C}$, under microaerophilic conditions. This led to the incorporation of the identification process though the utilization of the colony appearance basis on the microscopic slide through the utilization of positive catalase and oxidase tests through the incorporation of the hippurate hydroliss test. The results were provided within 3 to 5 days of sample collection.

Parasites in stool samples were collected via the concentration technique through the incorporation of a permanently stained slide. Wet mounts of the sediments were later examined for motile protozoan trophozoites, cysts, and ocysts pertaining to Giardia lamblia, Cyclospora cayetanensis and Isospora belli.

The presence of norovirus and/or rotavirus was determined by obtaining viral ribonucleic acid (RNA) through the utilization of $140 \mu \mathrm{l}$ of a $10 \%$ faecal suspension plus a QIAamp viral RNA mini kit. A one-step instant real time polymerase chain reaction (RT-PCR) system was utilized to identify norovirus, group A human rotavirus and enterovirus $(1,2)$.

\section{Statistical analysis}

The study utilized the Pearson's $x^{2}$ test to assess the importance placed upon the variances identified within the among the measurements provided by the groups through the utilization of spearman's non-parametric correlation. Correlation analysis was conducted to assess the role of age and viral pathogens in gastroenteritis. 
TABLE 1. Sociodemographic characteristics of patients

\begin{tabular}{lcc}
\hline Variable & $\mathrm{n}$ & $\%$ \\
\hline Gender & 577 & 57.7 \\
$\quad$ Female & 423 & 42.3 \\
$\quad$ Male & $33(15-88)$ & \\
Age (median - range) & & \\
Age group, years & 303 & 30.3 \\
15-24 & 223 & 22.3 \\
$25-34$ & 124 & 12.4 \\
$35-44$ & 135 & 13.5 \\
$45-54$ & 107 & 10.7 \\
$55-64$ & 108 & 10.8 \\
$\geq 65$ & & \\
Residence & 849 & 85 \\
Urban & 151 & 15 \\
Rural & & \\
\hline
\end{tabular}

\section{RESULTS}

One thousand patients complied with the inclusion criteria, which was stipulated for a period of two years. The median age of the patients was 33 (15-88) years, with 577 (58\%) being females, $\mathrm{p}<0.01$ (Table 1 ). The median age of male patients was 35 (15-87) years while the median age of females was 32 (15-88 years), which provides an approximate of $\mathrm{p}=0.3$. The majority of the cases $(303 ; 30.3 \%)$ were within the 15-24 years age group through the provision of an age difference identified at $\left(\chi^{2}=189.5 \mathrm{p}<0.001\right)$ (Figure 1). Patients below 35 years of age accounted for $52.5 \%$ of the total cases identified. The majority of cases identified lived in urban areas $(849 ; 85 \%), p<0.01$. The hospital admitted patients all year, but bacterial infections were more prevalent in the summer, and viral pathogens were more prevalent in the autumn (Figure 2). A total of 917 (91.7\%) of patients had a laboratory examination. The most common pathogen identified among the patients was Salmonella, which was identified in 174 (19\%) patients (Figure 3). The prevalent serotypes were the Salmonella serotype Enteritidis accounting for $31 \%$, and the Salmonella serotype Typhimurium, which accounted for $19 \%$. Norovirus together with rotavirus were identified through the utilization of RT-PCR, accounting for $83(9 \%)$ and $64(7 \%)$ of patients respectively.

Enterovirus was identified in $18(2 \%)$ of the patients, with five being co-infected with bacteria. An increase in age was associated with an increase in the detection of viral pathogens $(\mathrm{p}<0.01)$. Of the $28(3 \%)$ Shigella isolates, the most recurrent species were Shigella flexneri and Shigella sonnei, accounting for $46 \%$ and $21 \%$ respectively. Shigella dysenteriae and Shigella boydii accounted for $18 \%$ and $14 \%$ respectively. Esche-

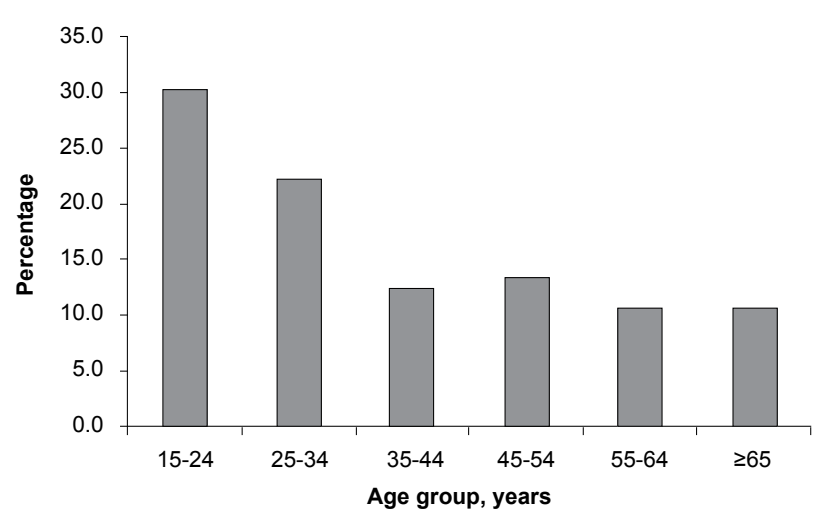

FIG. 1. Distribution of patients according to age group

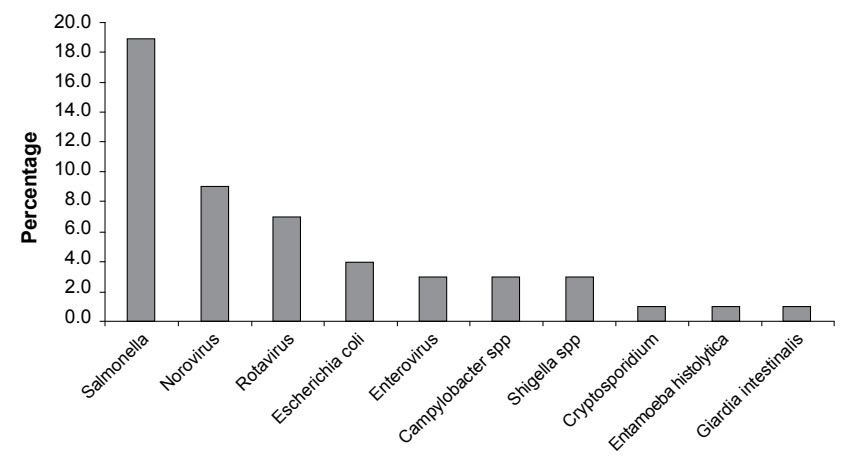

FIG. 2. Seasonal frequency occurrence of acute gastroenteritis

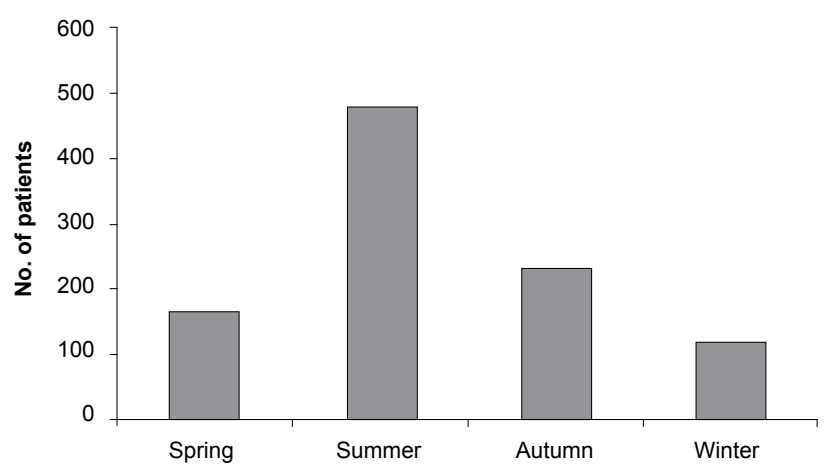

FIG. 3. Pathogens identified in patients with acute gastroenteritis

richia coli was found in $28(3 \%)$ patients. The prevalent types were enteroinvasive E. coli in $19(2 \%)$ patients and enteropathogenic E. coli in 9 (1\%) patients. Campylobacter spp. was detected in $28(3 \%)$ patients. Cryptosporidium was diagnosed in $9(1 \%)$ patients, Entamoeba histolytica in $7(0.8 \%)$ patients and Giardia intestinalis in $6(0.7 \%)$ patients. Overall, bacterial pathogens were identified in $29 \%$ of patients, viral pathogens in $19 \%$ and protozoal pathogens in $2.5 \%$ of patients. The study did not identify any aetiological agent or factor contributing to acute diarrhoea in 449 (49\%) patients. Multiple enteropatho- 
gens were diagnosed in $46(5 \%)$ patients: five $(10 \%)$ had two enteropathogens, and one ( $2 \%)$ had three.

The study isolated enteropathogens from stool samples of $61 \%$ of 468 patients who had positive tests. The specimens were collected within a day of onset of diarrhoea. The study identified 29 (3.2\%) patients in dire need of subsequent hospitalization due to the prevalence of the identified symptoms. These patients experienced more lengthy bouts of abdominal pain while in the ER (1.9 vs. 1 days, $p<0.01)$. Severe diarrhoea was more prevalent among patients infected with Salmonella (58\%) and Campylobacter (44\%), in comparison with a prevalence of $23 \%$ overall, $\mathrm{p}<0.01$. Vomiting was more common in patients with viral infections (63\%) in comparison to $33 \%$ of all patients, $\mathrm{p}<0.01$. Fever was prevalent among patients infected with Salmonella $(\mathrm{p}<0.01)$ and Campylobacter $(\mathrm{p}<0.01)$. Sixty-nine percent of patients admitted to hospital were suffering from severe illness and dehydration compared to $26 \%$ of outpatients with the same symptoms $(\mathrm{p}<0.01)$.

No patient reported experiencing circulatory shock at the time of presentation to the ER. In addition, there were no fatal outcomes during the study period.

\section{DISCUSSION}

This study presents the results of extensive laboratory investigations pertaining to a large sample of patients in a tertiary hospital, serving a mixed population that integrates people from different regions within the nation. This study seeks to provide a better understanding of the aetiologies and attributes of acute, community-acquired infectious gastroenteritis among adults identified within a university hospital in a developing country. A causative pathogen was identified in 51\% of patients.

Previous studies of diarrhoea in adult patients identified enteropathogens in $56 \%$ and $82 \%$ of patients $(15,16)$. The current study found bacterial pathogens in $29 \%$, viral pathogens in $19 \%$ and protozoal pathogens in $2.5 \%$ of patients. The most prevalent pathogens within the cohort were Salmonella, norovirus and rotavirus.

Acute gastroenteritis of viral origin is a common cause of hospital visits among the majority of the population within developed countries. In the United States, the most prevalent pathogens were norovirus (26\%), rotavirus (18\%), and Salmonella species (5.3\%) (17).

The current study observed a higher prevalence of viral infection than studies conducted within industrialized countries, where rotavirus and norovirus were identified in less than $5 \%$ of patients $(15,18)$. As well as reflecting an increased prevalence of viral infections, this may be attributed to increased utilization of sensitive detection methods (RT-PCR) within routine diagnostics involved in pathogen identification (19).
Increased prevalence of viral pathogens with an emphasis on the rotavirus leading to the identification of severe gastroenteritis among children and adults is paramount within the diagnostics and prevention processes integrated pertaining to the infections. Salmonella was the most prevalent pathogen, being found in $19 \%$ of patients. The most frequent serotype was Salmonella serotype Enteritidis (31\%). Similar results were found in 2002 and 2003, in Patra, Greece, where the most frequently isolated serotype among Salmonella was also $S$. Enteritidis (68\%), followed by $S$. Typhimurium (19\%), S. Newport (7\%), and S. Infantis (4\%) (20).

In the last 20 years, $S$. Enteritidis has been the most frequently isolated Salmonella serotype within Europe, where it has been attributed to $85 \%$ of salmonellosis cases identified (21). This study found Shigella in 3\% of patients, which was lower than the $10.8 \%$ reported in another study $(22,23)$. Campylobacter spp. was diagnosed in $28(3 \%)$ patients. Other studies found that $13 \%$ and $35 \%$ of the patients diagnosed by serology and by positive stool culture $(15,16)$. This study found multiple enteropathogens in $5 \%$ of patients. The correlation between the identified symptoms and the organism identified varied. Salmonella-positive patients had a higher body temperature than others. Shigella-positive patients had the highest probability of experiencing bloody diarrhoea. Campylobacter-positive patients experienced more lengthy periods of abdominal pain at presentation, and low levels of dehydration, thus limiting their need for intravenous fluid therapy.

Several factors may have contributed to the low levels of diagnostic yield within the study. For the majority of patients, only one faecal specimen was analysed, and the delay between sample delivery and processing differed. Thirteen percent of the patients had been treated with antibiotics within 2 weeks of onset of diarrhoea. In addition, the number of specimens required for optimal detection of enteropathogens has not been properly defined, but depends on the intensity of microbial excretion and the sensitivity of diagnostic methods utilized within the laboratory. A short duration of symptoms prior to sampling and frequent bowel movements should provide a higher yield. The study identified Cryptosporidium among $1 \%$ of patients, Entamoeba histolytica in $0.8 \%$ of patients and Giardia intestinalis in $0.7 \%$ of patients; these rates were low in relation to a study reporting Giardia intestinalis in $2 \%$ and Cryptosporidium in 2\% (15).

This study suggests that two or three samples should be collected to ensure that the necessary amounts are available to enhance the detection of the prevalent enteropathogens in the event that the first sample provides negative results. Routine testing of all patients with diarrhoeal diseases is clinically and cost-ineffective as the diagnostic yield is low and diagnosed cases identifying a single element of the entire diagnosis. Further research should place more emphasis on the need to make a thorough diagnosis at an individual level, especially in severe- 
ly ill patients, nosocomially infected patients, those involved in outbreaks or other epidemiologically important occurrences, or the very young or very old (24). Clinical features were identified at mild levels with frequency identified in vomiting whereas patients with bacterial infections showed more severe symptoms in comparison to other patients $(25,26)$.

Enteric infections among adults are a problem within developing countries and treatment is based on clinical features. Routine testing among all patients with diarrhoeal diseases involves high costs as the diagnostic yield is low and diagnosed cases identify a sample of the individuals diagnosed with gastroenteritis. The majority of authors suggest that stool cultures should be restricted to patients with severe symptoms pertaining to dehydration, toxicity or immune-compromise $(1,2,3)$. The prescribed treatment procedure incorporates hydration aimed at relieving the symptoms, preventing further spread of infection, and the provision of antibiotics empirically for indicated cases. The majority of the identified pathogens are countered through the administration of antibiotic treatment. However, this is not required in the event that the symptoms improve by the time that the culture results are available (11, 1, 2,3). Generally, the disease is mild in developing countries, without complications in other organs and systems $(23,27,28)$.

Except in the event that epidemiological or clinical evidence pertaining to a specific pathogen is identified, the study results indicate that testing for acquired pathogens among admitted adults within the nation should only incorporate tests for norovirus and rotavirus. The study found that the majority of patients had recovered by the time that culture-positive results were available, and no additional antimicrobial treatment was necessary $(1,2,3)$. These findings show that stool cultures have a limited ability to influence patient management for the majority of patients. The results also suggest that it is important to identify the value of empirical antibiotic treatment among patients suffering from infectious diarrhoea.

In summary, a pathogen was identified among half of the adult patients hospitalized with acute gastroenteritis. Stool culture studies are pertinent as they aid clinicians in developing clinical algorithms through the utilization of empirical antibiotics. This enhances the decision-making processes pertaining to outpatient and in-patient management programmes.

Ethics Committee Approval: Ethics committee approval was received for this study from the Ethics Committee of University of Tirana.

Informed Consent: Written informed consent was obtained from patients who participated in this study.

Peer-review: Externally peer-reviewed.

Author contributions: Concept - G.P.S.; Design - G.P.S.; Supervision D.V.K., P.S.P.; Resource - M.M.D.; Materials - M.M.D., S.Y.S.; Data Collection\&/or Processing - M.M.D.; Analysis\&/or Interpretation - G.P.S.; Literature Search - S.Y.S.; Writing - G.P.S.; Critical Reviews - S.F.B.
Conflict of Interest: No conflict of interest was declared by the authors.

Financial Disclosure: The authors declared that this study has received no financial support.

\section{REFERENCES}

1. World Health Organization. The Global Burden of Disease: 2004 update. Geneva, Switzerland: World Health Organization, 2008. Available from: http://www.who.int/healthinfo/global burden disease/GBD report 2004update full. pdf. Accessed 3 March 2013

2. World Health Organization. Water Sanitation and Health. Geneva, Switzerland: World Health Organization, 2004. Available from: http://www. who.int/water sanitation health/monitoring/jmpfinal. pdf. Accessed 25 February 2013

3. World Health Organization. The treatment of diarrhoea, a manual for physicians and other senior health workers. - $4^{\text {th }}$ revision. Geneva, Switzerland: World Health Organization, 2005. Available from: http:// whqlibdoc.who.int/publications/2005/9241593180.pdf. Accessed 20 February 2013

4. World Health Organization. Guidelines for the control of shigellosis, including epidemics due to Shigella dysenteriae type 1. Geneva, Switzerland: World Health Organization, 2005. Available from: http://whqlibdoc. who.int/publications/2005/9241592330.pdf. Accessed 20 February 2013

5. World Health Organization. Cholera outbreak: Assessing the outbreak response and improving preparedness. Geneva, Switzerland: World Health Organization, 2004. Available from: https://icvanetwork.org/system/files/versions/doc00003922.pdf. 20 February 2013

6. Walker CL, Black RE. Diarrhoea morbidity and mortality in older children, adolescents, and adults. Epidemiol Infect 2010;138:1215-26. [CrossRef]

7. Greco D, Luizzi I, Sallabanda A, Dibra A, Kakarricy E, Shapo L. Cholera in the Mediterranean: Outbreak in Albania. Euro Surveill 1995;1-2.

8. World Health Organization. Diarrhea. WHO. Available from: http:// www.who.int/topics/diarrhoea/en/

9. Forsberg BC, Petzold MG, Tomsona G, Allebeck P. Diarrhoea case management in low - and middle-income countries - an unfinished agenda. Bull World Health Organ 2007;85:42-8. [CrossRef]

10. Jamison DT, Breman JG, Measham AR, et al., editors. Disease control priorities in developing countries. 2nd edition. Washington (DC): World Bank; 2006.

11. Dupont HL. Guidelines on acute infectious diarrhea in adults. The Practice Parameters Committee of the American College of Gastroenterology. Guidelines on acute infectious diarrhea in adults. Am J Gastroenterol 1997;92:1962-75.

12. Cheng AC, McDonald JR, Thielman NM. Infectious diarrhea in developed and developing countries. J Clin Gastroenterol 2005;39:757-73. [CrossRef]

13. Thielman NM, Guerrant RL. Clinical practice. Acute infectious diarrhea. $N$ Engl J Med 2004;350:38-47. [CrossRef]

14. World Gastroenterology Organization practice guideline: Acute diarrhea March 2008. Available from: http://www.worldgastroenterology.org/assets/downloads/en/pdf/guidelines/01_acute_diar rhea.pdf

15. Svenungsson B, Lagergren A, Ekwall E, Evengård B, Hedlund KO, Kärnell A, et al. Enteropathogens in adult patients with diarrhea and healthy control subjects: A 1-year prospective study in a Swedish clinic for infectious diseases. Clin Infect Dis 2000;30:770-8. [CrossRef]

16. Andreas J, Klaus S, Jan K, Eckart S, Ralf I, Oliver L, et al. Aetiology of community-acquired, acute gastroenteritis in hospitalised adults: A prospective cohort study. BMC Infect Dis 2008;8:143. [CrossRef]

17. Bresee JS, Marcus R, Venezia RA, Keene WE, Morse D, Thanassi $\mathrm{M}$, et al. US Acute Gastroenteritis Etiology Study Team. J Infect Dis 2012;205:1374-81. [CrossRef] 
18. de Wit MA, Koopmans MP, Kortbeek LM, van Leeuwen NJ, Vinjé J, van Duynhoven YT. Etiology of gastroenteritis in sentinel general practices in the netherlands. Clin Infect Dis 2001;33:280-8. [CrossRef]

19. Lopman B, Vennema H, Kohli E, Pothier P, Sanchez A, Negredo A, et al. Increase in viral gastroenteritis outbreaks in Europe and epidemic spread of new norovirus variant. Lancet 2004, 363:682-8. [CrossRef]

20. Maraki S, Georgiladakis A, Tselentis Y, Samonis G. A 5-year study of bacterial pathogens associated with acute diarrhoea on the island of Crete, Greece, and their resistance to antibiotics. Eur J Epidemiol 2003;18:85-90. [CrossRef]

21. Galanis E, Wong DMALF, Patrick ME, Binsztein N, Cieslik A, Chalermchaikit T, et al. Web-based Surveillance and Global Salmonella Distribution, 2000-2002. Emerg Infect Dis 2006;12:381-8. [CrossRef]

22. Chan SS, Ng KC, Lyon DJ, Cheung WL, Cheng AF, Rainer TH. Acute bacterial gastroenteritis: a study of adult patients with positive stool cultures treated in the emergency department. Emerg Med J 2003;20:335-8. [CrossRef]
23. Munk Petersen A, Vinther Nielsen S, Meyer D, Ganer P, Ladefoged K. Bacterial gastroenteritis among hospitalized patients in a Danish county, 1991-93. Scand J Gastroenterol 1996;31:906-11. [CrossRef]

24. Hines J, Nachamkin I. Effective use of the clinical microbiology laboratory for diagnosing diarrheal diseases. Clin Infect Dis 1996;23:1292301. [CrossRef]

25. Park S, Giannella R. Approach to the adult patient with acute diarrhea. Gastroenterol Clin North Am 1993;22:483-97.

26. Casburn-Jones AC, Farthing MJG. Management of infectious diarrhea. Gut 2004;53:296-305. [CrossRef]

27. Presterl E, Nadrchal R, Wolf D, Rotter M, Hirschl AM. Enteroaggregative and enterotoxigenic Escherichia coli among isolates from patients with diarrhea in Austria. Eur J Clin Microbiol Infect Dis 1999;18:209-12. [CrossRef]

28. Svanteson B, Thorén A, Castor B, Barkenius G, Bergdahl U, Tufvesson B, et al. Acute diarrhoea in adults: aetiology, clinical appearance and therapeutic aspects. Scand J Infect Dis 1988;20:303-14. [CrossRef] 